UDC: $811.11: 371.314 .6 \quad$ https://doi.org/10.22190/JTESAP2101001H

Review research paper

\title{
DEVELOPING CRITICAL THINKING IN READING COMPREHENSION OF TEXTS FOR SPECIFIC PURPOSES AT ALL LEVELS OF BLOOM'S TAXONOMY
}

\author{
Božena Horváthová, Lýdia Nad’ová \\ Constantine the Philosopher University in Nitra, Faculty of Education, Slovakia
}

\begin{abstract}
This study tackles the role of ESP teacher, course design, teaching techniques, and evaluation procedures. It further focuses on evaluating teaching techniques which should improve students' reading comprehension which operates at multiple levels, by applying Bloom's six levels to in-class reading tasks. To accomplish this, twelve B2 level students engaged in activities that revolve around their reading of a text for specific purposes. Through these activities, teaching techniques were assessed and students comprehension was evaluated on each of the six levels. The activities used for research at level 1 were done in person in the classroom. The research activities for levels 2-6 were arranged through an eLearning platform, and students worked independently to complete them and return them to the teacher via internet. The research method used was action research. Based on the findings, it is aimed to offer answers and suggestions that may be useful for EAP and ESP teachers. The research has shown that using reading comprehension strategies at all levels of Bloom's taxonomy in achieving comprehension is beneficial not only in language education, but also for the development of the higher order thinking skills of adolescents. It equips them with the ability to think critically and creatively, and provides them with vital tools that they will use during their whole life.
\end{abstract}

Key words: English for specific purposes, reading comprehension, Bloom's taxonomy, critical thinking

\section{INTRODUCTION}

The objective of the article is to provide theoretical and practical knowledge regarding an exploration of how principles of Bloom's taxonomy can be applied to reading comprehension for language learners in EAP and ESP classes in order to find the most suitable strategies for assessing students' reading comprehension proficiency at each of the six levels of Bloom's taxonomy. Reading comprehension according to Bloom's taxonomy can be looked at from many angles. Is reading and remembering the content from a text proof of sufficient comprehension? Are there other levels which need to be investigated? Is the expansion of reading strategies appropriate for adolescents? Are

Submitted October $18^{\text {th }}, 2020$, accepted for publication October $26^{\text {th }}, 2020$

Corresponding author: Božena Horváthová, Constantin the Philosopher University in Nitra, Faculty of Education Drazovska 4, 94974 Nitra, Slovakia|E-mail: olcan@etf.rs 
all students able to reach all levels of Bloom's taxonomy? By which strategies can we check their comprehension? This article aims to address these questions.

The methods and principles of Bloom's taxonomy, strategies of reading comprehension, materials, time management, and the practice of receptive skills for reading comprehension activities are combined with productive skills of writing and developing creativity and critical thinking.

Since the main emphasis of the article lays on using reading comprehension strategies at all levels of Bloom's taxonomy in an upper secondary school setting, we introduced a topic related to reading comprehension alongside activities that were used among adolescents. At this age learners' cognitivity is developing as a result of improvement in their ability to think abstractly and to consider hypothetical items, which is often demonstrated through their creative approaches to arguments.

This paper preferably concentrates on the reading skills presented in CEFR for learners of a foreign language at the B2 level. According to CEFR, a proficient, B2 level foreign language user is able to read for overall ideas, for specific information, for detailed understanding, and for implications (Council of Europe, 2001). During reading activities, a B2 reader can process written texts by one or more writers, and can master activities that require them to read for general concepts and specific information. They can read and follow directions. They are also proficient enough in the foreign language to read for pleasure.

\section{ENGLISH FOR SPECIFIC PURPOSES AND DEVEloping COMMUNICATIVE SKILLS}

According to Strevens (1988: 1-2) English for Specific Purposes (ESP) meets "specified needs of the learner, related in content to particular disciplines, occupations, and activities, centered on the language appropriate to those activities, in syntax, lexis, discourse, semantics, etc". In addition, Robinson (1980) states that ESP courses are determined in all essentials by the prior analysis of the communication needs of the learners and of the context. ESP courses are fundamentally pragmatic in their interests and are strongly oriented to practice in the selection of relevant genre exemplars, language items, and instructional tasks from real-world contexts. Subject matters may include themes or topics governed by students' needs, purposes, and interests, or any subject in their curriculum.

According to Kováčiková (2020: 27) ESP or EAP is the term that has traditionally been used for courses which aim at teaching English language needed for specific situations, mainly related to academic or occupational contexts. Kováčiková (2020) further states that ESP prepares students for the real world through learner-centred tasks by developing their languages skills with learning how to read, write, listen to, and speak about selected content, for example, by working with authentic reading materials that require students to interpret and evaluate a text in oral or written form.

\section{READING COMPREHENSION AS A COMMUNICATIVE SKILL IN EAP AND ESP}

Studies done by The Collaboration of English Councils of Teachers (2013-2014) indicate the importance of two reading subskills of equal priority levels: word recognition and language comprehension. Both of these are a part of the process of teaching students to read. Word recognition is when students are able to recognize a written word by pronunciation when they read it. Language comprehension is the ability of students to 
interpret words and ideas and their wider meanings by grasping not only the exact meaning of the words or ideas, but also the meaning between the lines.

The word 'comprehend' comes from a Latin root meaning to 'wrestle with something'. Many teens who find reading challenging are perfectly capable of accurately recognizing and reading individual words; rather they struggle (or 'wrestle') with understanding the words as a whole and fail to comprehend the overall meaning of what they are reading (National Institute for Literacy, 2004). Snow (2002) found that at least two things are necessary to succeed in reading comprehension. First, students must be active readers, and secondly, they need to interact and be committed to the written text.

Reading comprehension requires smaller steps and is considered to be a process. According to Duke (2003: 44), reading comprehension allows students to interact with a text at many different levels while drawing from their previous background and experiences. Becoming a good reader hinges on an ability to employ strategies to make meaning from the text, thereby achieving comprehension (National Institute for Literacy, 2004). Küçükoğlu (2013) writes that there is a requirement for the process and strategies of reading comprehension to be described. She adds that students have to be entrusted with numerous reading activities by their teachers. These activities can include making predictions, making connections, visualizing, inferring, asking questions, and summarizing. Teachers should give teenagers the freedom to understand a text by observing, listening, understanding, and independently experiencing.

Küçükoğlu (2013: 709) reckons that in learning reading comprehension there are three crucial procedures that need to be completed: to clarify what type of an educational strategy is reasonable for a task and how to employ that strategy; to show students the entire operation of the activity; and to let the students try the strategy themselves through exercises and activities in various settings such as in pairs or small groups. Keenan et al. (2008) stress that teachers need to prepare a varied range of strategies for comprehension reading, so students can test their knowledge at different skill levels and through different processes.

The results of active reading comprehension include an ability to engage with a text based on their previous experiences both from reading and from life. Snow (2002) explains that outcomes often take the form of the students' inputs and responses, which indicate their level of understanding. Beside the direct outcomes of reading comprehension, understanding the text, there are also very beneficial indirect outcomes for students who master reading comprehension. Yuliana (2019) points out that teens with the finest results in reading comprehension are more likely to read for pleasure, to excel in intellectual content, and even to be successful in achieving later life goals.

Reading comprehension takes on another layer of complexity when the text being read is a text for specific purposes and it is provided in a foreign language. Even though students have the skills to read and know the basic English vocabulary and grammar, this does not automatically translate to their understanding of an academic or specific English text as a whole. Students will still need to acquire the academic vocabulary specific to the topic they are reading about in order to begin to understand the text and then build comprehension to higher-order levels of thinking (Park, 2010). 


\section{BLOOM’s TAXONOMY AND ITS SIGNIFICANCE IN EAP AND ESP}

Bloom's taxonomy was created by Benjamin Bloom in 1956. It consists of six levels and is often illustrated as a pyramid. Krathwohl (2002) states that Bloom saw these six levels as more than only an instrument for assessing the results of understanding. Scully (2017) underlines that Bloom did not make a clear distinction between lower order and higher order thinking. For this reason, the taxonomy was revised in 2001 by Anderson and Krathwohl (Anderson et al., 2001), leaving its original number of six categories for measuring cognitivities, but specifying these levels into two groups to better classify the thinking skills they required. The first three levels (remember - recall facts and basic concepts; understand - explain ideas or concepts; and apply - use information in new situations to solve problems) constitute the Lower-Order Thinking Skills (LOTS). The last three levels (analyse - take apart information to show relationships, causes and connections; evaluate - justify a stand or a position; and create - produce something new) are considered Higher-Order Thinking Skills (HOTS). Scully (2017) explains that by reaching the highest level of the pyramid in a certain skill, students become equipped to face more sophisticated and more practical challenges in their future. Fastiggi (2014) suggests that students should be challenged by their teachers to solve more difficult tasks for their cognitive thinking.

In order to achieve HOTS, a student first needs to master LOTS. Even though students may complain about memorizing, it is important that they can achieve the lower levels in order to build a foundation for later, higher-order levels. If they are to use a concept in real life, they first must understand that concept. Without understanding, they will never gain the abilities to analyse and evaluate. In order to reach authentic comprehension and proficiency, they must progress through the entire pyramid. In other words: "before you can understand a concept, you must remember it. To apply a concept, you must first understand it. In order to evaluate a concept, you must have analysed it. To create an accurate conclusion, you must have completed a thorough evaluation" (Shabatura, 2018). This applies to how the research of this paper is structured and what levels students were evaluated on.

Bloom's taxonomy prepares students for training their cognitive skills, as it is equipped with a hierarchical order for cognitive proficiencies (Fastiggi, 2014). As Fastiggi (2014) points out it has practically been used all over the world, supporting productivity of lessons and evaluation of students' learning. Helpful characteristics of the taxonomy include its orientation for education, its categorized groups of objectives; the clear and rational explanation of each comprehension level; and the progression of the levels from the easiest one to the most difficult one. Bloom's taxonomy is helpful for teachers in many ways, and can be used as a framework for delivering appropriate activities, assessments, questions, learning objectives, and intended outcomes (Persaud, 2018). According to Gershon (2013), it guides teachers towards creating lessons more easily and with clear objectives. By asking specific questions to differentiate between Bloom's levels, teachers can check the comprehension of their students throughout the learning process. According to Surjosuseno and Watts (1999: 227), Bloom's taxonomy is a helpful tool for making sure that students are challenged at every level of proficiency during the learning process, from lower order thinking skills to higher order thinking skills. Fastiggi (2014) states that as an educational framework Bloom's Taxonomy can be applied to any cognitive content and that, regardless of the subject, the taxonomy is a practical tool for teachers to use because it outlines a framework for planning lessons that challenge and help students to reach their potential. It is appropriate to use Bloom's taxonomy as a guideline for helping B2 level students achieve reading proficiency in a foreign language (Ornstein, 1990; Council of Europe, 2001; CEFR: 69-71, 96). 


\section{RESEARCH}

The following part introduces and describes the research, including its methods, principles, materials, time management, and rubrics. Firstly, research aims and questions are specified. Secondly, the participants are introduced and described. Next, research methods are presented. Finally, the results are analysed and interpreted, and conclusions are drawn.

\subsection{Research Aims and Research Questions}

The paper has the following research objectives:

1. To explore how the principles of Bloom's taxonomy can be applied to reading comprehension of a text for specific purposes in foreign language teaching.

2. To find the most useful strategies for assessing students' reading comprehension proficiency at each of the six levels of Bloom's taxonomy.

Based on the objectives, the following research questions were established and explored throughout the study.

1. How can the principles of Bloom's taxonomy be applied to reading comprehension of a text for specific purposes in teaching English as a foreign language?

2. What strategies are most useful in assessing reading comprehension proficiency at each of the six levels of Bloom's taxonomy?

\subsection{Participants}

The research involved students studying in a five-year programme focused on English as a foreign language in the fifth grade of upper secondary school level at an Evangelic bilingual grammar school in Slovakia. The language instruction contains general English classes and English for Specific Purposes (ESP) classes. The ESP classes include core academic subjects, such as history, geography, maths, physics, and religion. The research was conducted with twelve B2 level students aged 19-21 in March and April 2020. Six religion lessons were taught which consisted of eight reading comprehension activities according to the six levels of Bloom's taxonomy.

\subsection{Research Methodology}

The decision to follow the methodology of action research was made because the researcher had observed weak reading skills and a lack of overall comprehension among her students during former reading exercises and wished to improve their reading skills and comprehension.

The action research consists of phases which are repeated in a cycle, since the researcher must collect information, then adapt and restructure his/her methods. The aim is to continually improve the actions in order to achieve higher quality results through the educational process. The researcher must choose what problem he or she wants to solve, and how the task should be managed. Further, the researcher must choose what steps and methods to use for the research. Next, the researcher must collect data, analyse it, and interpret the results. Based on these interpretations, the researcher chooses the best strategy to apply to the educational process. The methods are adapted, new data is collected, interpreted, and evaluated, and the results are compared to the previous round of analysis. These steps can be repeated as many times as necessary in order to continually improve the strategies being studied and achieve the best results. 
The principles of action research lent themselves well to this study's focus. The researcher set out to discover how the principles of Bloom's taxonomy could be used to develop reading comprehension of a text for specific purposes at the upper secondary school level. To demonstrate this, activities and learning objectives were developed for each of the six levels. After the completion of each level the researcher evaluated what could have been more useful and adapted the next level's activities and objectives accordingly. The research followed the four stages of action research for each level: planning, implementing, observing, and reflecting (Latief, 2012). Between each round of research, the researcher evaluated what could be improved and adapted the rounds that followed accordingly.

To achieve the objectives, a 'catalogue' (checklist) was used which equalled a written form of testing characterized by objectivity and economy. Tasks were created to test the students' proficiency at each specific level. Their fulfilment of each task was then graded according to an established rubric for that level. Because each level was handled differently, the specific methodology for each level is described in detail in the following teaching sessions which constitute the most important part of the whole research process.

\section{RESEARCH RESULTS}

\subsection{Level 1: Remember}

According to Ornstein (1990), this level is defined as "the most basic, requiring the least amount of cognitive rigour. This is about students recalling key information, for example, the meaning of a word". Verbs for level 1 are remember, include, define, name, order, describe, recite, recognise, label, recall, record, list, relate, reproduce, match, repeat, state, arrange, underline.

Planning and Implementation: Two different activities were used to address the first level of Bloom's taxonomy, remembering. Through these activities, students were asked to demonstrate their ability to recall facts and basic concepts. First, students were given 21 words selected by the teacher from the "Essay on Forgiveness" by C.S. Lewis, which they had not yet read. They were also given 21 definitions separately and in a random order. Students were divided into groups of 2-3 and told to work together to match the definitions on one side with the selected words. They were given 10 minutes to complete this exercise. The teacher did not immediately check the answers. Secondly, students were given the text "Essay on Forgiveness" and told to read the essay individually by skimming and looking for the overall idea. After they had completed this, they were asked to read the essay a second time for more detail. Under the text the definitions from the first activity were written. These were divided into two groups of word definitions: 10 words in the first 3 paragraphs and 11 words in the final 4 paragraphs, making a total of 21 words. Students were told to find the words from the previous activity in the text based on the definitions at the bottom of the page. They were given 20 minutes to complete this activity. These series of activities measured students' ability to scan quickly through a longer and complex text to find specific information - in this case vocabulary words that they had been introduced to before reading the text - according to the CEFR requirements. Students were asked to match words with definitions, recognize and underline those same words in the given text, and recall the definitions of the words through the quizlet exercises. 
Evaluation Method and Results: Because the activities for level 1 were entirely objective, students' answers were checked against a key of the correct answer and given a percentage grade to evaluate proficiency at the remembering stage. Of the 12 students who completed the level 1 matching activity, 9 students scored between 90-100\%, 1 student between $80-90 \%, 0$ between $70 \%-80 \%, 2$ between $60-70 \%$, and 0 below $60 \%$. In the second exercise, finding the words in the text, 9 students scored between $90-100 \%, 1$ between $80-90 \%, 2$ between $70 \%-80 \%$, and 0 below 70\%. The averages of all scores were $88.1 \%$ and $88.5 \%$ respectively.

Observation and Reflection: Overall, the researcher was pleased with the results of the activities from level 1 . However, she noticed that many students made the same mistakes in the second activity as the mistakes from the first, showing little or no improvement between levels. She believed this was due to the fact that feedback was not given as promptly as it could have been given following the first exercises. Moving forward, the methods were adapted and the researcher resolved to give more prompt and consistent feedback while students completed the future tasks and to see how this change impacted the results of the following levels.

\subsection{Level 2: Understand}

According to Ornstein (1990), at this level, "the student who recalls the definition of a word, for example, would also be able to show understanding of the word by using it in the context of different sentences". This level includes verbs such as arrange, explain, interpret, classify, express, locate, describe, identify, and report.

Planning and Implementation: To show that they had achieved the second level of Bloom's taxonomy, students were given an activity that demonstrated their ability to explain ideas and concepts from the text they had read. Students were told to read the text again, this time with the following list of comprehension questions:

- Why is forgiveness mentioned in Christian Creed?

- How do you understand God's forgiveness?

- What is the difference between forgiving and excusing?

- What can be misunderstood by asking God's forgiveness?

- Describe what words combination 'extenuating circumstances'+ mean?

- Write down two remedies, which are helping to forgive?

- What is the difference between forgiving other people who hurt you and the one in which you are asking God's forgiveness?

- How can we forgive?

At this stage, students were reminded to answer the questions according to the ideas expressed in the text, not according to their own opinions and ideas. The researcher had resolved to give more prompt and consistent feedback to students throughout the remaining levels. Students were asked to demonstrate understanding of the main ideas of the text, identify new ideas, and grasp the overall meaning of the text as outlined in CEFR requirements for B2 English proficiency in reading. Students were asked to identify answers to the given questions within the text, and then restate those answers in their own words. Their answers to the various discussion questions were expected to describe, explain, and discuss those answers in written form. Throughout level 2, the teacher checked their students' understanding of the text through questions that are designed to measure understanding of the overall meaning and main themes of the text. The students had to grasp information from 
what they read and use this information to interpret the text as a whole in order to demonstrate understanding of the relationships between the ideas expressed in the text as it was presented.

Evaluation Method and Results: Like the activities for level 1, the activity for level 2 was also mostly objective, although there was expected to be some variance in how students phrased their answers. The main evaluation method was to measure each student's answers against a key and ensure that the students understood what the main ideas of the article were and what points the author was trying to make, as opposed to what their own personal opinions on the topic were. Of the 12 students 2 students scored between 80-90\%, 5 (most of the students) between $70 \%-80 \%, 1$ between $60-70 \%, 3$ between $50-60 \%$, 0 between 40 $50 \%$, and 1 below $40 \%$. The average of all scores was $66.7 \%$.

Observation and Reflection: The results of level 2 were significantly lower than those from level 1. Students had struggled to follow the directions of the task and to understand the overall objective. In order to improve this, the researcher adapted the methodology to include a rubric for each level that showed students what objectives they would be evaluated by. These rubrics are displayed in the "Evaluation Methods" sections for the remaining levels. The researcher expected that this more explicit outlining of activity objectives would give students a clearer idea of how to approach the future activities.

\subsection{Level 3: Apply}

As Ornstein (1990) states, "this usually involves students answering questions or solving problems". Verbs like apply, practice, solve, use, prepare, demonstrate, schedule, demonstrate, operate, sketch, and measure are used at level 3.

Planning and Implementation: Students were given a series of journaling prompts to demonstrate their ability to use information in new situations according to the third level of Bloom's taxonomy. Students were asked to choose two out of a series of five questions, reflect on them, and write a one-page journal response on their own reflections and ideas. The journaling prompts given were as followed:

- Summarise an article into 2-3 sentences; write self-reflection how you see forgiveness after reading?

- Pick up two things that surprised you or interested you? Explain why?

- What's going on within you when you forgive those who assault you?

- Have you ever forgiven someone? How did you feel about and what you have learnt from it? Either way IF nothing or something - explain your answer.

- How does forgiveness apply to your life? IF does or does not - explain your answer.

According to the methodology adaptations, students were also given an evaluation rubric that outlined the specific objectives they were expected to achieve.

This activity measured students' ability to summarise a text and highlight important ideas from the text as a whole. These tasks aligned with CEFR requirements for B2 language learners reading comprehension abilities. Students were asked to apply the concepts of the text to their own lives and demonstrate the application by writing about their personal experiences and thoughts in relationship to the text. In doing so they were expected to consider how the theme of forgiveness could be measured and/or used in their own lives. Throughout level 3, the students' degree of fluency and spontaneity of the tasks completion was checked. The teacher was able to determine students' independence as readers and to check their ability to adapt what they read to different texts and purposes - in this case to their own lives and experiences. 
Evaluation Method and Results: Level 3 was evaluated out of 15 points according to the following rubric. The left column lists the aspects of the exercise that were evaluated. The remaining columns are labelled 1 (being the fewest number of points that a student could earn per category) to 5 (the maximum number of points per category) for the teacher to evaluate how effectively that aspect was accomplished. Of the 12 students 4 (most of the students) scored between $90-100 \%, 1$ between $80-90 \%, 1$ between $70 \%$ $80 \%, 1$ between $60-70 \%, 2$ between $50-60 \%, 1$ between $40-50 \%$, and 2 below $40 \%$. The average of all scores was $68.9 \%$.

Table 1 Evaluation Rubric for Level 3 Apply

\begin{tabular}{|c|c|c|c|}
\hline & $\mathrm{No}$ & Partly & Fully \\
\hline $\begin{array}{l}\text { Does the journal display an } \\
\text { understanding of important ideas from } \\
\text { the text? }\end{array}$ & & & \\
\hline $\begin{array}{l}\text { Does the journal show that the student } \\
\text { is capable of APPLYING the ideas } \\
\text { from the article to his or her own life or } \\
\text { experiences? }\end{array}$ & & & \\
\hline $\begin{array}{l}\text { Does the journal demonstrate that the } \\
\text { student CONSIDERED the theme of } \\
\text { forgiveness in the article and how it } \\
\text { connects to his or her life? }\end{array}$ & & & \\
\hline
\end{tabular}

Observation and Reflection: Upon observing the results of level 3, the researcher was pleased to see a slight improvement from the results of level 2. However, after reflecting on students' work, she observed that many students were taking aspects of the reading text out of context and struggling both to grasp the whole picture of the text and to differentiate between themes and key ideas. To adapt the methodology accordingly, she resolved to create clearer guidelines and boundaries for future activities. These boundaries were designed to give students freedom to think critically about the text as they chose, but to help guide them in such a way that they could differentiate between the topics at hand. For example, in the activities for levels 4 and 5, skeleton graphs and tables were provided for students to fill out, giving them specific boxes or columns to fill out, but freedom to choose what textual evidence they used to do so. For level 6, students were given predetermined parameters to help start them on the right track for their creative projects, but were allowed to be creative within those parameters.

\subsection{Level 4: Analyse}

According to Ornstein (1990), this level is defined as "students being able to draw connections between ideas, thinking critically, to break down information into the sum of its parts." Verbs for level 4 include analyse, diagram, question, calculate, discriminate, test, categorise, distinguish, differentiate, contrast, examine, compare, criticise, experiment, and inventory. 
Planning and Implementation: Students were given the task of completing a Venn diagram to demonstrate their ability to draw connections between ideas. Through this activity, students showed their mastery of the fourth level of Bloom's taxonomy. Students were asked to read back through the text looking for information on two specific aspects of the article, and to consider these questions: What does Lewis say about how God forgives? What does Lewis say about how people forgive? What do they have in common? What is different about them?

Then, using the information they found in the article, they were instructed to fill out a Venn diagram as an adaptation to the methodology based on previous levels' results. Students could choose what information to use to complete the chart, but the chart was designed to guide them in the right direction in order to avoid common errors of taking key aspects of the text out of context. Each of the three sections was to be filled with 3-4 points. This series of activities measured students' ability to comment on and discuss contrasting ideas within a text, according to the CEFR requirements. Students were asked to categorise statements and concepts from the text, distinguishing between two similar but different themes: God's forgiveness and human forgiveness. Using these statements and concepts, they were to compare and contrast the two themes and to demonstrate the process on the Venn diagram. Throughout level 4, the teacher checked how well students could process the text in the context of modern issues, and break down what they have read and make connections between concepts, taking into consideration the writer's viewpoint. Teachers should be aware that this level, which expects students to demonstrate higher order thinking, can be challenging for some students.

Evaluation Method and Results: The students' work for level 4 was evaluated out of 29 points according to the following rubric and calculated as a percentage. Table 4 depicts the rubric used to evaluate students' performance on level 4's Venn diagram activity. The top part of the table has columns for marking how many of the required points the student included in each column of the Venn diagram (rows 1-4). For the second part of the table, the left column lists the aspects of the exercise that were evaluated. The remaining columns are labelled 1 (being the fewest number of points that a student could earn per category) to 5 (the maximum number of points per category) for the teacher to evaluate how effectively that aspect was accomplished. Of the 12 students 2 students scored between $90-100 \%, 1$ student between $80-90 \%, 1$ between $70 \%-80 \%, 0$ between $60-70 \%, 2$ between $50-60 \%, 4$ (most students) between $40-50 \%$, and 2 below $40 \%$. The average of all scores was $58.0 \%$.

Observation and Reflection: Unfortunately, the results of level 4 were much lower than any of the previous levels. This indicated that the adaptations made between levels 3 and 4 had not proven to be adequate. The researcher noticed that in addition to taking aspects of the text out of context, students seemed to struggle with the abstract themes of the reading such as God, sin, and forgiveness. In order to adapt the methodology accordingly, the researcher resolved to incorporate more tangible ideas into the remaining levels. For instance, level 5 deals with parables, in which abstract concepts are given more tangible representations. Level 6 offers tangible outcomes (i.e. blog posts, podcasts, and collages) as a means for students to express their critical thinking about abstract themes. 
Table 2 Evaluation Rubric for Level 4 Analyse

\begin{tabular}{|l|l|l|l|l|l|}
\hline $\begin{array}{l}\text { How many accurate points are in the } \\
\text { section "God's forgiveness"? }\end{array}$ & 0 & 1 & 2 & 3 & \\
\hline $\begin{array}{l}\text { How many accurate points are in the } \\
\text { section "people's forgiveness"? }\end{array}$ & & & & & \\
\hline $\begin{array}{l}\text { How many accurate points are in the } \\
\text { centre section? }\end{array}$ & $\begin{array}{c}\text { No } \\
1\end{array}$ & 2 & $\begin{array}{c}\text { Partly } \\
3\end{array}$ & 4 & $\begin{array}{c}\text { Fully } \\
5\end{array}$ \\
\hline $\begin{array}{l}\text { The student's work displays an ability } \\
\text { to comment and discuss multiple ideas } \\
\text { in the text. }\end{array}$ & & & & & \\
\hline $\begin{array}{l}\text { The student was able to effectively put } \\
\text { statements and concepts into their } \\
\text { appropriate categories. }\end{array}$ & & & & & \\
\hline $\begin{array}{l}\text { The student demonstrated an ability to } \\
\text { COMPARE two ideas. }\end{array}$ & & & & & \\
\hline $\begin{array}{l}\text { The student demonstrated an ability to } \\
\text { CONTRAST two ideas. }\end{array}$ & & & & & \\
\hline
\end{tabular}

\subsection{Level 5: Evaluate}

According to Ornstein (1990) at this level "students can make accurate assessments or judgements about different concepts. They can make inferences, find effective solutions to problems and justify conclusions, while drawing on their knowledge and understanding". This level includes verbs such as arrange, design, prepare, assemble, formulate, propose, collect, manage, set up, compose, organise, synthesise, create, plan, write, construct, modify, and conduct.

Planning and Implementation: To show that they had achieved the fifth level of Bloom's taxonomy, students were given an activity that demonstrated their ability to justify a decision. To complete this activity, students needed to combine their understanding of the Lewis text with two additional readings. They were asked to read two of Jesus' parables about forgiveness from the Bible, texts found in Matthew 18:21-35 and Luke 7:36-50. After reading, they needed to evaluate each story by filling out a chart that covered the following 5 questions according to the C.S. Lewis article about forgiveness: Summarize the passage (2-3 sentences), What does the parable say about God's forgiveness?, How does the forgiveness of God in this parable relate to C.S. Lewis's article?, What is man's relationship with forgiveness in the parable?, How does the forgiveness of man (or the lack of forgiveness by man) in this parable relate to C.S. Lewis's article?

Based on the previous levels' results the additional readings that students were given for level 5 included tangible representations of the more abstract themes explored in the C.S. Lewis text. This activity was designed to engage students with level 5 of Bloom's taxonomy, evaluate, and therefore the actions required of students involved verbs identified as part of this level: assemble, collect, set up, organise, and synthesise. To demonstrate these skills, students were asked to collect data from two outside texts and evaluate them according to the overall meaning of Lewis's original text. They should 
then synthesise and organise the ideas and assemble them into the given table as a visual means of setting up thematic connections. Throughout level 5, the teacher should check students' ability to process outside material for new information or arguments and connect these external ideas with the original text. Students should show ability to apply what they find in the text to their own experiences. Teachers should pay attention to students' ability to make inferences, find effective solutions to problems, and justify conclusions.

Evaluation Method and Results: Level 5 was evaluated out of 30 points according to the following rubric, and calculated as a percentage. Table 5 depicts the rubric used to evaluate students' performance on level 5's activity. The left column lists the aspects of the exercise that were evaluated. The remaining columns are labelled 1 (being the fewest number of points that a student could earn per category) to 5 (the maximum number of points per category) for the teacher to evaluate how effectively that aspect was accomplished. Of the twelve students, 2 students scored between $90-100 \%, 2$ students between $80-90 \%, 3$ between $70 \%-80 \%$, 0 between $60-70 \%, 2$ between $50-60 \%, 3$ between $40-50 \%$, and 0 below $40 \%$. The average of all scores was $73.3 \%$.

Table 3 Evaluation Rubric of Level 5 Evaluate

\begin{tabular}{|c|c|c|c|c|c|}
\hline & $\begin{array}{c}\text { No } \\
1\end{array}$ & 2 & $\begin{array}{l}\text { Partly } \\
3\end{array}$ & 4 & $\begin{array}{c}\text { Fully } \\
5\end{array}$ \\
\hline $\begin{array}{l}\text { Number of boxes accurately filled out } \\
\text { for the first parable (Matthew 18). }\end{array}$ & & & & & \\
\hline $\begin{array}{l}\text { Number of boxes accurately filled out } \\
\text { for the second parable (Luke 7). }\end{array}$ & & & & & \\
\hline $\begin{array}{l}\text { The student demonstrated the ability to } \\
\text { COLLECT data from outside texts. }\end{array}$ & & & & & \\
\hline $\begin{array}{l}\text { The student demonstrated the ability to } \\
\text { EVALUATE data from the outside texts } \\
\text { according to the original text. }\end{array}$ & & & & & \\
\hline $\begin{array}{l}\text { The student demonstrated the ability to } \\
\text { ORGANISE ideas from both texts and } \\
\text { place them in the chart appropriately. }\end{array}$ & & & & & \\
\hline $\begin{array}{l}\text { The student's work demonstrated that } \\
\text { they had made connections between the } \\
\text { THEMES of the original article and the } \\
\text { two parables. }\end{array}$ & & & & & \\
\hline
\end{tabular}

Observation and Reflection: The results of level 5 were a significant improvement over the results of level 4 , indicating that providing tangible representations helped the students process more abstract ideas. One observation the researcher made following level 5 was that some students were still struggling to back up connections with explanation or evidence. It was clear that the students were beginning to grasp the themes from the C.S. Lewis text, but when evaluating their work, it was difficult for the researcher to follow the connections they were making. In order to remedy this, the researcher made a final adaptation to the final level of research, and added a component to the requirements for the creative project by asking every student to write a one-page explanation of how their project connected to the text and its key points. 


\subsection{Level 6: Create}

The most complex level of Bloom's taxonomy is defined by Ornstein (1990) as "the ultimate aim of students' learning journey [where] students demonstrate what they have learnt by creating something new, either tangible or conceptual". Verbs such as appraise, estimate, select, argue, evaluate, support, assess, judge, value, attack, predict, score, compare, rate, and defend are used at the sixth and final level.

Planning and Implementation: Students were given a list of project choices to demonstrate their ability to produce original work according to the final level of Bloom's taxonomy, creating. They were asked to choose one of the following options to demonstrate their understanding of C.S. Lewis's essay about forgiveness:

- Create a collage or piece of art that represents forgiveness based on C.S. Lewis's definition and write a one-page explanation of the finished product and how it related to the original text.

- Create a 10-minute podcast during which the student and a friend discussed C.S. Lewis's view of forgiveness and how it applies to life in the 21 st century. To conclude, the students should write a one-page explanation of the finished product and how it related to the original text.

- Create a blog post where the student invented and responded to the letters of two people needing advice on different problems surrounding the theme of forgiveness. The student would then answer the questions through the blog post as if he/she was C.S. Lewis. To conclude, the students should write a one-page explanation of the finished product and how it related to the original text.

Each option given to students for their creative project required them to write a one-page explanation that demonstrated the connection of their work to the text itself in order to help them think through and process their interaction with the text. Students were asked to demonstrate what they had learned by creating something new. They were given options of tasks to demonstrate their learning. These tasks asked them to create scenarios and then predict how the author of the original text might respond, evaluate the theme of the text in a modern day context and argue for whatever conclusion they came to, or create a piece of art that they felt represented the text and then support their creation. Regardless of which activity the student chose, they were required to engage with the text at the sixth and final level of Bloom's taxonomy. Throughout this level, the teacher should evaluate students' ability to make judgements about the ideas and arguments that they read in the text in the context of either external or internal criteria. Teachers should encourage students to prioritize what they learn as they form their conclusions and challenge them to pay attention to the insights they gain while relating this knowledge to "real-world" situations.

Evaluation Method and Results: Level 6 was evaluated out of 25 points according to the following rubric, and calculated as a percentage. Table 6 depicts the rubric used to evaluate students' performance on level 6's activity. The left column lists the aspects of the exercise that were evaluated. The remaining columns are labelled 1 (being the fewest number of points that a student could earn per category) to 5 (the maximum number of points per category) for the teacher to evaluate how effectively that aspect was accomplished. Of the 12 students 5 (the most students) scored between 90-100\%, 3 between $80-90 \%$, 1 between $70 \%-80 \%$, 0 between $60-70 \%, 1$ between $50-60 \%$, 0 between $40-50 \%$, and 2 below $40 \%$. The average of all scores was $76.3 \%$. 
Table 4 Evaluation Rubric for Level 6 Create

\begin{tabular}{|l|l|l|l|l|l|}
\hline & $\begin{array}{c}\text { No } \\
1\end{array}$ & 2 & $\begin{array}{c}\text { Partly } \\
3\end{array}$ & 4 & \begin{tabular}{c} 
Fully \\
\hline $\begin{array}{l}\text { The student's project was one of the } \\
\text { given options. }\end{array}$
\end{tabular} \\
\hline $\begin{array}{l}\text { The project demonstrated } \\
\text { CREATIVITY. }\end{array}$ & & & & & \\
\hline $\begin{array}{l}\text { The project demonstrated CRITICAL } \\
\text { THINKING. }\end{array}$ & & & & & \\
\hline $\begin{array}{l}\text { The project effectively demonstrated } \\
\text { what the student had learned from } \\
\text { their work with the original text. }\end{array}$ & & & & & \\
\hline $\begin{array}{l}\text { The project demonstrated that the } \\
\text { student had ENGAGED with the text } \\
\text { and its ideas. }\end{array}$ & & & & & \\
\hline
\end{tabular}

Observation and Reflection: Overall, the researcher was pleased with the results of level 6. One aspect that she might change in the future is to develop a more structured way for the teacher to check in with the students throughout the creative process to make sure they are on the right track.

\section{INTERPRETATION OF THE RESEARCH RESULTS}

The majority of students demonstrated that they had thought critically about the concept of Lewis's forgiveness during their completion of the assignments. This indicated that the tasks had been effective as a whole. To evaluate each level more specifically, the data from each of the assignments was analysed, as discussed in the following paragraph.

When looking at the data from all six levels of activities, the strongest results were produced at level 1, remembering. Of the 12 students, 9 achieved scores in the $90 \%-100 \%$ range for both of the level 1 exercises. Additionally, no students scored below $60 \%$ on the level 1, which cannot be said of any other level's results. The averages of all students' level 1 scores were $88.1 \%$ and $88.5 \%$, the highest average of all the levels. These results show that level 1 was the level in which the most students showed proficiency. As level 1 is the most fundamental of the six levels, these results are not surprising. The data also indicates that the activities in level 1, specifically the matching and word finding activities, proved most effective for students.

The data shows that student achievement was lowest in level 4, analyse. The average overall score for level 4 was $58.0 \%$. Level 4 had the highest number of students with scores below $60 \%$ ( 8 of 12 students). This indicates that level 4 proved the most challenging for students, and supports the conclusion that the activity used in this level, specifically asking students to complete the Venn diagram comparing and contrasting two ideas, was less effective in teaching students than those in other levels. The results at the other 4 levels $-2,3$, 5 , and 6 fell between those from levels 1 and 4 . The average scores at these levels were $66.7 \%, 68.9 \%, 69.4 \%$, and $76.3 \%$ respectively. As these scores are considered sufficient for a passing grade, they indicate that the activities used to teach the corresponding levels were 
effective, but also have room for some improvement in order to have more students achieving higher results and to improve the overall level of comprehension for all students as indicated by a higher average score.

\section{CONCLUSION}

Two research questions were stated before the research itself took place. The first research question was "How can the principles of Bloom's taxonomy be applied to reading comprehension in teaching English as a foreign language?" According to our research, this can be done by breaking down the aspects of reading comprehension into six levels to mirror Bloom's taxonomy. As shown in the research, by creating activities that measure student's comprehension based on the listed verbs from each level, an instructor can effectively test and evaluate each student's comprehension at the targeted level. The second research question was "What strategies are most useful in assessing proficiency at each of the six levels of Bloom's taxonomy?" The average score for all strategies fell within the range of a passing grade since no average score fell below $50.0 \%$. Therefore, all strategies can be considered generally useful. However, some were certainly more useful than others.

Based on the research, we can state that the most effective strategies were those used to assess levels 1 and 6 . These activities include matching and finding words within a text to measure students' ability to remember key information, and open-ended, project-based creative activities to measure student's ability to think critically and creatively based on what they learned from a text. The least effective strategy was the diagram used to assess level 4, in which students had to compare and contrast two key ideas from the text.

The previous lines presented the conclusions of the research in light of the established research questions. Firstly, the results of the research pointed to the need to focus on each level separately. Interesting to observe was improvement on levels of Bloom's taxonomy where some respondents got less percentage in lower levels, but the sixth level for them was excellent. Students were permanently challenged with the same text (they read it at least six times) during quite a short time. So, the researcher could observe progress in adolescents' cognitive development. On the other hand, it would be engaging to further study why some students did excellently at all five of the first levels, but could not create something new when asked.

ACKNOWLEDGMENT. The paper includes research results gained as a part of the project APVV-15-0368 Prax $v$ centre odborovej didaktiky, odborová didaktika $v$ Centre praktickej pripravy/Practice in the centre of the subject field didactics, subject field didactics in the centre of preparation for practice. 


\section{REFERENCES}

Anderson W. and Krathwohl, D. R. 2001. A Taxonomy for Learning, Teaching, and Assessment. A revision of Bloom's Taxonomy of educational objectives. USA: Addison Wesley Longman, Inc.

Council of Europe. 2001. Common European Framework of References for languages: Learning, Teaching, Assessment. [ed.] Cambridge University Press. Strasbourg: Language Policy Unit.

Duke, K. Nell. 2003. Comprehension instruction for informational text. What Research Says About Reading. 61(6), 40-44.

Fastiggi, W. 2014. Applying Bloom's Taxonomy to the Classroom. [Online] 2014. [Accessed on 05. 03 2020.] Retrieved from https://technologyforlearners.com/ applying-bloomstaxonomy-to-the-classroom.

Gershon, M. 2013. How to use Bloom's Taxonomy in the classroom. [ed.] TES Connect Digital Publishing.

Keenan, M. J., Betjemann, R. S. and Olson, R.K. 2008. Reading comprehension tests vary in the skills they assess: Differential dependence on decoding and oral comprehension. [ed.] Psychology Department. Scientific Studies of Reading. 3, 12(3), 281-300.

Kováčiková, E. 2020. English for Specific Purposes in Higher Education through Content and Language Integrated Learning. Newcastle UK: Cambridge Scholars Publishing.

Krathwohl, R. D. 2002. A revision of Bloom's taxonomy: An overview. Theory Into Practice. 41 (4).

Küçükoğlu, H. 2013. Improving reading skills through effective reading strategies. ProcediaSocial and Behavioral Sciences. (70), 709-714.

Latief, M. A. 2012. Research method on language learning: Introduction. Malang: UM Press.

Lewis, C.S. 1960. Essay on Forgiveness. Macmillan Publishing Company, Inc. N.Y.

Ornstein, A. 1990. Strategies for Effective Teaching - T. F. Revised Bloom's Taxonomy and Performance Tasks Wheel. New York: HarperCollins Publishers.

Park, Y.-H. 2010. Korean EFL College Students' Reading Strategy Use to Comprehend Authentic Expository/Technical Texts in English. [dissertation] University of Kansas.

Persaud, Ch. 2018. Bloom's Taxonomy: The Ultimate Guide. [Online] [Accessed on 25. 03 2020.] Retrieved from https://tophat.com/blog/blooms-taxonomy-ultimate-guide.

Robinson, P. 1980. ESP (English for Specific Purposes). Pergamon.

Scully, D. 2017. Constructing Multiple-Choice Items to Measure Higher-Order Thinking. Practical Assessment, Research, and Evaluation (PARE), 22 (4).

Shabatura, J. 2018. Using Bloom's Taxonomy to Write Effective Learning Objectives. [Online]. [Accessed on 22. 03 2020.] Retrieved from: https://tips.uark.edu/using-bloomstaxonomy/. Best Practices, Course Design.

Snow, C. E. 2002. Reading for understanding: toward a research and development program in reading comprehension. Santa Monica, CA: RAND.

Strevens, P. 1988. ESP after twenty-years: A re-appraisal. In M. Tickoo (Ed.), ESP: State of the art (pp. 1-13). Singapore: SEAMEO Regional Language Centre.

Surjosuseno, T. T. and Watts, V. 1999. Using Bloom's Taxonomy to teach reading in English as a foreign language classes. Queensland Journal of Educational Research (QJER), $15(2), 227-244$

The collaboration of English Councils. 2013-2014. Teachers' Guide to Reading Comprehension Strategies P5-S3: Edinburgh Literacy Hub. 